\title{
ASSESSMENT OF OCCUPATIONAL DOSE IN FLUOROSCOPY PROCEDURES WHEN INDIVIDUAL MONITORING IS NOT UTILIZED*
}

\author{
Olivera Ciraj-Bjelac ${ }^{* *}$, Danijela Arandjic1, Predrag Bozovic' ${ }^{1}$, Sandra Ceklic ${ }^{2}$, Jelena \\ Stankovic ${ }^{1}$, Djordje Lazarevic ${ }^{2}$
}

${ }^{1}$ University of Belgrade, School of Electrical Engineering and Vinca Institute of Nuclear Sciences, Belgrade, Serbia

${ }^{2}$ University of Belgrade, Vinca Institute of Nuclear Sciences, Belgrade, Serbia

\begin{abstract}
Fluoroscopy procedures may lead to increased radiation exposure of radiologists and other staff members. The objective of the study is to assess whole body radiation doses and doses to the eye in fluoroscopy procedures, based on measurements that allow for estimates of occupational doses when personal dosimeters have not been used. Four geometrical configurations were considered: overcouch $x$-ray tube with and without table mounted lead rubber curtains in place, undercouch $x$-ray tube with horizontal $x$-ray beam and undercouch $x$-ray tube with vertical $x$-ray beam. The doses were estimated using distribution of the scattered radiation and typical workload, as well as the pattern of used of protective tools. Estimated effective dose was in the range from few to $60 \mu \mathrm{Sv}$ per procedure for radiologist, and from few to $20 \mu \mathrm{Sv}$ per procedure for radiographer, depending on the geometrical configuration and level of personal protection. Corresponding unprotected eye doses were estimated to be in the range $0.03-2.8 \mathrm{mSv}$ per procedure for radiologist and 0.02-0.78 $\mathrm{mSv}$ for radiographer. The presented results allowed for realistic estimations of the occupational whole body dose and dose to the eyes from the workload of the staff members and from the level of use of radiation protection tools when personal dosimeters have not been regularly used.
\end{abstract}

Key words: fluoroscopy, radiation dose, eye lens dose, scatter radiation, $x$-rays.

DOI: $10.21175 / \operatorname{RadJ} .2016 .01 .011$

\section{INTRODUCTION}

The use of $\mathrm{x}$-rays for diagnostic or interventional procedures has increased in recent years. Fluoroscopy unit are of particular concern because of potential for delivering relatively high exposures to staff and patients. Among other categories of professional exposure, occupational exposure in fluoroscopy in one of the area in which increased exposure is likely to occur, in particular for certain organs as extremities including eye lens [1-4]. As the eye lens is one of the most radiosensitive tissues in the human body, occupational exposure to radiation has become a real concern for many medical professions, in particular for interventional medical staff since it may lead to the development of lens opacities [5-7].

During these procedures, if staff remain near the $x^{-}$ ray source and within a high scatter radiation fields for several hours per day, and do not use radiological protection tools and methods, the risk may become substantial [5]. The primary operators who usually stay longer and stand closer to the patient's right side are most likely to receive the highest exposure among all staff involved in interventional procedures [8]. In addition, there have been recent reports of opacities detected in the lens of the eye among some groups of healthcare workers using fluoroscopy in interventional radiology and cardiology $[7,9,10]$. If these effects are seen in interventional radiology and cardiology, the potential for such effects exists for other uses of fluoroscopy outside imaging departments. Apparently, this appears to be the only circumstance where occupational exposures to ionizing radiation may be routinely resulting in clinically observable tissue reactions [5].

In most clinical situations individual monitoring is performed using a single dosimeter aimed for whole body dose assessment or using two dosemeters positioned under and above the lead apron (double dosimetry). Although double dosimetry is well established in interventional procedures and recommended by numerous professional organizations, practical utilization of this approach is not well known mainly in terms of availability and correctness in use of two dosimeters among fluoroscopy staff. In addition, many studies reported irregular use of personal dosimeters [11, 12], and even if used, it position on the body remains uncertain. Contrary to whole body dosimetry, eye dosimetry is not well established. Numerous studies have highlighted many drawbacks in monitoring occupational exposure in fluoroscopy including the lack of comprehensive personal dose records [11, 13].

Many professionals are still working without using (or not using regularly) any existing simple radiation protection tools (e.g., ceiling suspended screen, glasses) or/and without personal dosimeters [11, 13]. In the cases where personal dosimeters have not been used regularly, the approaches taken to estimate retrospectively the dose to staff members often use approach based on the availability of values from experimental measurements made at certain positions

\footnotetext{
* The paper was presented at the Third International Conference on Radiation and Applications in Various Fields of Research (RAD 2015), Budva, Montenegro, 2015.

${ }^{* *}$ Contact: ociraj@vinca.rs
} 
at the fluoroscopy room, representative of the typical position of the particular staff members. To improve the accuracy, these measurements are usually made without the protection of the ceiling suspended screen, and the obtained scatter dose values can be corrected by the attenuation factor of the protection tools used [11].

The objective of this study is to assess whole body radiation doses and doses to the eye in fluoroscopy rooms, based on measurements that allow for estimates of occupational doses when personal dosimeters have not been used.

\section{METHODS}

Four geometrical configurations were considered: overcouch x-ray tube with and without table mounted lead rubber curtains in place, undercouch $x$-ray tube with horizontal $\mathrm{x}$-ray beam and undercouch $\mathrm{x}$-ray tube with vertical $\mathrm{x}$-ray beam (Figure 1). Scatter radiation dose rate was measured using a calibrated dosimeter in terms of operational dosimetric quantity $\mathrm{H}^{*}(10)$, in the presence of the water phantom $25 \mathrm{~cm} \mathrm{x} 25 \mathrm{~cm} \mathrm{x} 15 \mathrm{~cm}$ as a scattering medium using a calibrated pressurized ionizing chamber Victoreen $451 \mathrm{P}$ (Fluke Biomedical, USA). The dose rate measurements ware performed in steps of $20 \mathrm{~cm}$ from 40 to $200 \mathrm{~cm}$ from the floor in vertical direction and from 20 to $100 \mathrm{~cm}$ from patient table side in horizontal direction [14]. Therefore, scatter radiation dose was measured in the plane perpendicular and plane parallel to the $\mathrm{x}$-ray bema axis in steps of $20 \mathrm{~cm}$. The measured values were further interpolated to obtain isodose curves.

Two models of conventional x-ray units were used for measurements: Superix 1250, Telestatix (EI Nis) with overcouch X-ray tube geometry and Superix 1250, Undistat (EI Nis) with undercouch x-ray tube geometry.

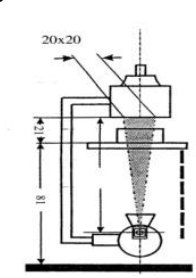

a

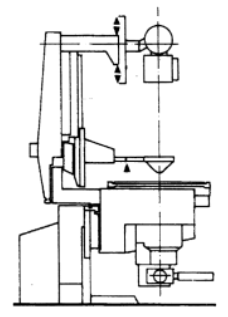

c

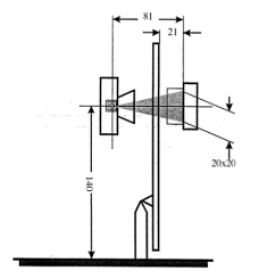

b

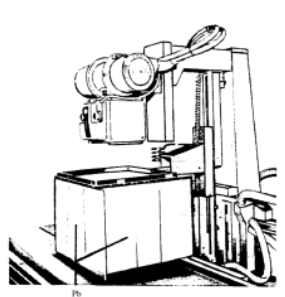

d
Figure 1.Irradiation geometry: undercouch, vertical beam (a), undercouch tube, horizontal beam (b), overcouch tube, no protection (c), overcouch tube with protection (d)

These results were used for assessment of weighted surface dose, i.e. surface dose at position of a particular organ contribution to the effective dose, as this quantity could be used as a conservative estimation of the effective dose. The position of organs was deduced from the MIRD5 mathematical phantom [15, 16]. Information on typical exposure parameters was taken from clinical practice (average: $95 \mathrm{kV}, 3 \mathrm{~mA}, 10 \mathrm{~min}$ of fluorospy time and 6 exposures/examination of 82 $\mathrm{mAs}$ each) and was further used to assess effective dose and eye dose for radiologist and radiographer performing a fluoroscopy procedure. The weighted surface dose was calculated using a $\mathrm{H}^{*}(10)$ value at a level of each particular organ and ICRP tissue weighting factor [15]. This quantity was calculated for a typical position of radiologist and radiographer for each irradiation geometry. Effective dose was further estimated using following equation:

$$
\tilde{E}_{k}=I \cdot t \cdot H_{k, p}+n_{g} \cdot m A s \cdot \dot{H}_{k, g}
$$

where, $t$ is fluoroscopy time, $I$ is tube current in fluoroscopy mode, $n_{g}$ is number of images, $m A s$ tube loading per image and $\dot{H}_{k, p}, \quad \dot{H}_{k, g}$ are wiighted surface doses for fluorosopy and radiography in $\mu \mathrm{Sv} / \mathrm{mAs}$, respectively. Typical exposure paarmeter for fluorosopy rpocedures were used to assess the efective dose. Furthermore, different arrangements of personal protective tools were considered, as aprons of $0.25 \mathrm{~mm}, 0.35 \mathrm{~mm}$ and $0.5 \mathrm{~mm}$ lead equivalence and combination of lead apron and collar shielding of 0.25 $\mathrm{mm}$ lead equivalence. Eye lens dose assessment was assessed based on the information on the typical exposure parameters and scatter dose rate at the level of $160 \mathrm{~cm}$ at the position of radiologist and radiographer.

\section{RESULTS AND DISCUSSION}

The radiation profiles are presented in Figs. 2-5. The essential difference in radiation safety between two types of fluoroscopic unit configurations lies in scattered radiation aspects which has a huge impact on the occupational exposure.

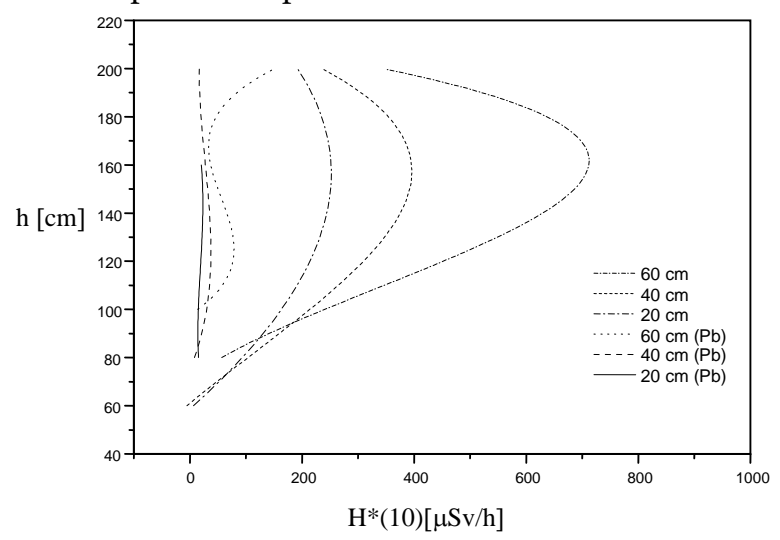

Figure 2. Vertical scatter radiation profiles for $80 \mathrm{kV}$, for an overcouch $\mathrm{X}$-ray tube fluoroscopic installation. $\mathrm{Pb}$ indicates the presence of protective drapes/curtains. 


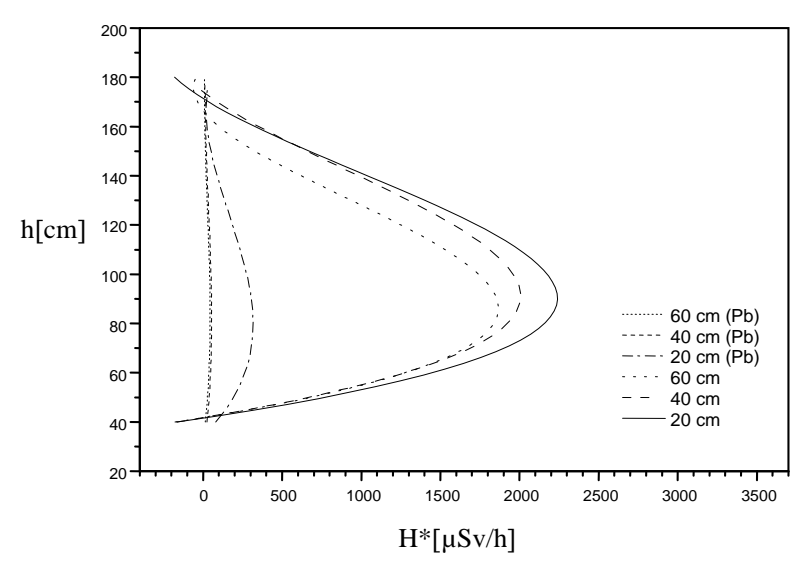

Figure 3.Vertical scatter radiation profiles for $8 \mathrm{o} \mathrm{kV}$, for an undercouch X-ray tube fluoroscopic installation, vertical x-ray beam. $\mathrm{Pb}$ indicates the presence of protective drapes/curtains

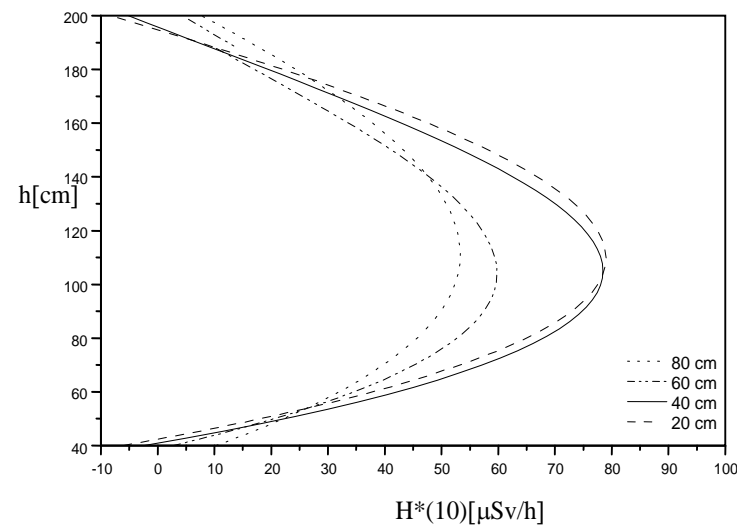

Figure 4. Vertical scatter radiation profiles in a vertical plane for an undercouch X-ray tube fluoroscopic installation, horizontal $\mathrm{x}$-ray beam.

Presented figures demonstrate that the protective tools have a considerable effect; with the screens removed the dose profiles are flattened in shape. On removal of these screens the dose rate is increased by more than factor of ten.

The resulting body exposure is extremely nonuniform. Under such conditions the partially unshielded organs in the trunk, together with tissues and organs in the head and neck region influence the effective dose. The eye lens dose is of particular concern. The assessed whole body and eye doses for different x-ray unit geometries and protective tool arrangements are presented in Table 1. Estimated effective dose was in the range from less than 0.01 to
0.06 $\mathrm{mSv}$ per procedure for radiologist, and from less than 0.01 to $0.02 \mathrm{mSv}$ per procedure for radiographer, depending on the geometrical configuration and level of personal protection. Corresponding unprotected eye doses were estimated to be in the range $0.03-2.8 \mathrm{mSv}$ per procedure for radiologist and $0.02-0.78 \mathrm{mSv}$ for radiographer. The highest exposures are associated with overcouch tube geometry and absence of table mounted protective tools.

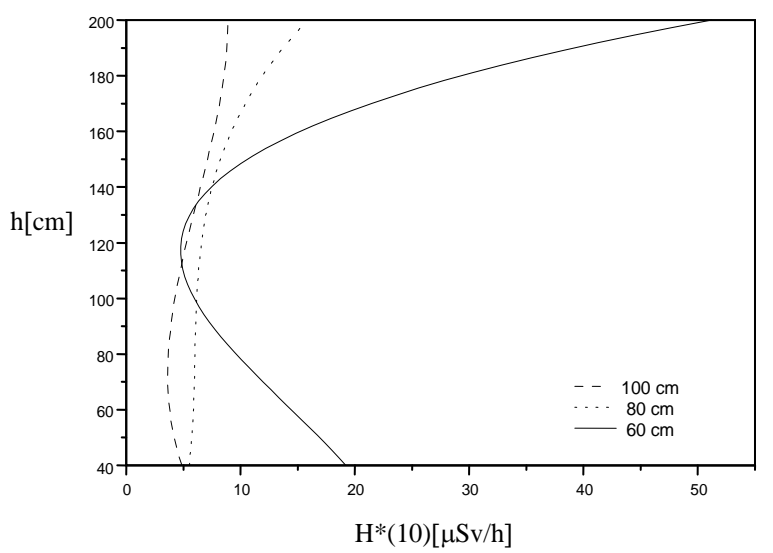

Figure 5. Vertical scatter radiation profiles in a vertical plane for an undercouch X-ray tube fluoroscopic installation, couch in vertical position

Major problems and sources of uncertainty in occupational dose assessment are related to the variations in staff positions and variable technical factors used during fluoroscopy, in particular fluoroscopy time and number of images or series.

It was assumed that the staff wears lead-rubber protective devices of different lead equivalent and transmission factor. Table 1 provides the weighted surface doses for the cases in with no protective clothing and for the for different types of personal protective devices. When applicable, a factor to take account of dose reduction achieved by the lead apron a partial body shielding was applied. In that manner, weighted surface dose contains contributions from organs lying outside the protective apron. The calculations were performed for protective aprons of lead equivalent of $0.25,0.35$ and $0.5 \mathrm{~mm}$ and for the combination of apron of lead equivalent of $0.35 \mathrm{~mm}$ and thyroid shield of lead equivalent of $0.25 \mathrm{~mm}$.

Similar calculations were performed to estimate eye doses and these values are also given in Table 1 . 
Table 1. Estimated doses to staff during fluoroscopic procedures

\begin{tabular}{|c|c|c|c|c|c|c|}
\hline \multirow{3}{*}{ Category of staff } & \multicolumn{6}{|c|}{ Dose per procedure $[\mathrm{mSv}]$} \\
\hline & \multirow{2}{*}{ No apron } & \multicolumn{4}{|c|}{ With apron (mm lead equivalent) } & \multirow{2}{*}{$\begin{array}{l}\text { Eye dose } \\
{[\mathrm{mSv}]}\end{array}$} \\
\hline & & 0.25 & 0.35 & 0.5 & $0.35+0.25^{*}$ & \\
\hline \multicolumn{7}{|l|}{ Radiologist } \\
\hline overcouch X-ray tube unit & 0.28 & 0.06 & 0.05 & 0.04 & 0.02 & 2.84 \\
\hline (without protective curtains) & $(0.08-0.67)$ & $(0.02-0.13)$ & (0.02-0.11) & (0.01-0.10) & $(0.006-0.05)$ & $(0.85-6.67)$ \\
\hline overcouch X-ray tube unit & 0.08 & 0.02 & 0.01 & 0.01 & & 0.20 \\
\hline (with protective curtains) & $(0.02-0.18)$ & (0.01-0.05) & $(0.003-0.02)$ & $(0.002-0.02)$ & $<0.01$ & $0.06-0.47)$ \\
\hline undercouch X-ray tube unit & 0.05 & 0.01 & 0.01 & 0.006 & $<0.01$ & 0.02 \\
\hline (horizontal) & $(0.02-0.12)$ & $(0.002-0.02)$ & (0.003-0.02) & (0.002-0.01) & & $(0.005-0.04)$ \\
\hline $\begin{array}{l}\text { undercouch X-ray tube unit } \\
\text { (vertical) }\end{array}$ & $\begin{array}{c}0.01 \\
(0.002-0.02)\end{array}$ & $<0.01$ & $<0.01$ & $<0.001$ & $<0.01$ & $\begin{array}{c}0.03 \\
(0.01-0.07)\end{array}$ \\
\hline \multicolumn{7}{|l|}{ Radiographer } \\
\hline overcouch X-ray tube unit & 0.16 & 0.02 & 0.02 & 0.02 & 0.01 & 0.78 \\
\hline (without protective curtains) & $(0.05-0.37)$ & (0.01-0.05) & (0.01-0.04) & (0.01-0.04) & $(0.003-0.02)$ & $(0.23-1.82)$ \\
\hline $\begin{array}{l}\text { overcouch X-ray tube unit } \\
\text { (with protective curtains) }\end{array}$ & $\begin{array}{c}0.04 \\
(0.01-0.08)\end{array}$ & $\begin{array}{c}0.01 \\
(0.002-0.02)\end{array}$ & $\begin{array}{c}0.01 \\
(0.002-0.02)\end{array}$ & $<0.01$ & $<0.01$ & $\begin{array}{c}0.06 \\
(0.02-0.15)\end{array}$ \\
\hline $\begin{array}{l}\text { undercouch X-ray tube unit } \\
\text { (horizontal) }\end{array}$ & $\begin{array}{c}0.04 \\
(0.01-0.10)\end{array}$ & $<0.01$ & $<0.01$ & $<0.01$ & $<0.01$ & $\begin{array}{c}0.04 \\
(0.01-0.10)\end{array}$ \\
\hline $\begin{array}{l}\text { undercouch X-ray tube unit } \\
\text { (vertical) }\end{array}$ & $<0.01$ & $<0.01$ & $<0.01$ & $<0.01$ & $<0.01$ & $\begin{array}{c}0.02 \\
(0.01-0.05)\end{array}$ \\
\hline
\end{tabular}

The data in the Table 1 emphasize the importance of wearing a lead apron. It is worth mentioning that increasing lead thickness above $0.35 \mathrm{~mm}$ dose not deliver much dose reduction, but substantially increase the apron weight. Additional thyroid shielding results in more completed shielding of the body, so the combination of apron of lead equivalent of $0.35 \mathrm{~mm}$ and thyroid shielding thickness of $0.25 \mathrm{~mm} \mathrm{~Pb}$ would be very efficient in reduction the effective dose.

Assuming a radiologist performs five procedures daily, five-day week, 48 week-year, a maximum of about 1200 examinations could be performed annually. In practice, in most cases annual workload is only a fraction of this number.

\section{CONCLUSIONS}

Scattered radiation rates in the vicinity of fluoroscopy equipment can be quite high, depending on type of fluoroscopic procedure and equipment configuration, as well as on the use of protective tools. In overcouch-tube fluoroscopy with the radiologist at the couch side, a significant dose to the eye may result from modest number of procedures. Under these circumstances, protective actions need to be taken.

In undercouch-tube fluoroscopy, the estimated dose is well within dose limits. Dose to eyes is, however, limiting factor. Consequently, wearing eye protective glasses should be mandatory.

In addition, it is important to consider personal monitoring arrangements for each type of procedure and equipment type, as the use of individual monitoring is the best way to track occupational exposure of an individual.

Presented methodology could be used as an option when individual monitoring is not available or regular. Using presented data, extrapolation to different diagnostics techniques can be applied, in respect to differences in workload, fluoroscopy time, exposure factors, field sizes and use of protective tools.

The presented results allowed for realistic estimations of the occupational whole body dose and dose to the eyes from the workload of the staff members and from the level of use of radiation protection tools when personal dosimeters have not been regularly used.

Acknowledgement:This work was supported by the Ministry of Education and Science of the Republic of Serbia (grant agreement 43009 and 171007).

\section{REFERENCES}

1. "Avoidance of Radiation Injuries from Medical Interventional Procedures, ICRP Publication 85," J. Valentin, Ed., Ann. ICRP 30, no. 2, June 2000.

2. K. Faulkner and B. M. Moores, "An Assessment of the Radiation Dose Received by Staff Using Fluoroscopic Equipment," Br. J. Radiol., vol. 55, pp. 272-276, May 1982.

3. E. Vano, N.J. Kleiman, A. Duran, M. Romano-Miller and M.M. Rehani, "Radiation-Associated Lens Opacities in Catheterization Personnel: Results of a Survey and Direct Assessments," J. Vasc. Interv. Radiol., vol. 24, no. 2, pp. 197-204, Feb. 2013.

4. E. Vano, N.J. Kleiman, A. Duran, M.M. Rehani, D. Echeverri and M. Cabrera, "Radiation Cataract Risk in Interventional Cardiology Personnel," Radiat. Res., vol. 174, no. 4, pp. 490-495, Oct. 2010.

5. M.M. Rehani et al.,. "Radiological Protection in Fluoroscopically Guided Procedures Performed Outside the Imaging Department. ICRP Publication 117 ," Ann. ICRP, vol. 40, no. 6, pp. 1-102, Dec. 2010.

6. International Commission on Radiological Protection. (April 21, 2011). ICRP ref 4825-3093-1464 Statement on Tissue Reactions. Retrieved from: http://www.icrp.org/docs/ICRP\%20Statement\%200 n\%20Tissue\%20Reactions.pdf

7. O. Ciraj-Bjelac, M. Rehani, A. Minamoto, K.H. Sim, H.B. Liew and E. Vano, "Radiation-Induced Eye Lens Changes and Risk for Cataract in Interventional 
Cardiology," Cardiology, vol. 123, no. 3, pp. 168-171, Oct. 2012.

8. Y. Kong, L. Struelens, F. Vanhavere, C.S. Vargas, W. Schoonjans, W.H. Zhuo, "Influence of Standing Positions and Beam Projections on Effective Dose and Eye Lens Dose of Anaesthetists in Interventional Procedures," Radiat. Prot. Dosim, vol. 163, no. 2, pp. 181-187, Feb. 2015.

9. E. Vano, L. Gonzalez, J.M. Fernandez, Z.J. Haskal. "Eye Lens Exposure to Radiation in Interventional Suites: Caution is Warranted," Radiol., vol. 248, no. 3, pp. 945-953, Sep. 2008.

10. E. Vano, L. Gonzalez, E. Guibelalde, J.M. Fernandez and J.I. Ten, "Radiation Exposure to Medical Staff in Interventional and Cardiac Radiology," Br. J. Radiol., vol. 71, pp. 974-96o, Sep. 1998.

11. E. Vano, J.M. Fernandez, R. Sanchez, L.T. Dauer, "Realistic Approach to Estimate Lens Doses and Cataract Radiation Risk in Cardiology When Personal Dosimeters Have not Been Regularly Used," Health Phys., vol. 105, no. 4, pp. 330-339, Oct. 2013.
12. C.J. Martin, "A Review of Radiology Staff Doses and Dose Monitoring Requirements," Rad. Prot. Dos., vol. 136, no. 3, pp. 140-157, Sep. 2009.

13. O. Ciraj-Bjelac, M.M. Rehani, "Eye Dosimetry in Interventional Radiology and Cardiology: Current Challenges and Practical Considerations," Rad. Prot. Dosim., vol. 162, no. 3, Nov. 2013.

14. Medical Electrical Equipment. Part 1: General Requirements for Safety. 3. Collateral Standard: General Requirements for Radiation Protection in Diagnostic X-Ray Equipment, IEC 601-1-3, 1994.

15. International Commission on Radiological Protection. (March, 2007). ICRP Publication 103: The 2007 recommendations of the International Commission on Radiological Protection.

16. Handbook of Anatomical Models for Radiation Dosimetry (Series in Medical Physics and Biomedical Engineering), 1st ed., X.G. Xu and K.F. Eckerman, Eds., CRC, Taylor and Francis, New York (NY), USA, 2009. 